\title{
Organizações como processos e Teoria Ator- Rede: A contribuição de John Law para os Estudos Organizacionais
}

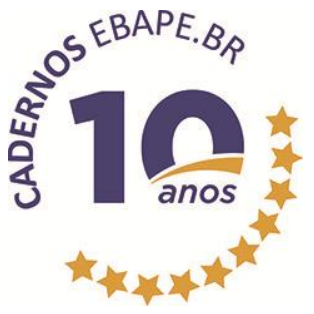

\section{Organizations as processes and Actor-Network Theory: John Law's contribution to Organizational Studies}

\author{
Maria Fernanda Rios Cavalcanti ${ }^{1}$ \\ Rafael Alcadipani ${ }^{2}$
}

\begin{abstract}
Resumo
Em anos recentes, muito se tem debatido a respeito de alternativas às ditas "abordagens representacionais" nos estudos das organizações. Tais discussões costumam destacar o aspecto processual e fluido da organização, que não pode ser tomada como um fim ou um objeto estático e, por isso, ela exige outras formas de explorar e compreender seu fenômeno. Uma abordagem que surge com relevante popularidade é a Teoria Ator-Rede (TAR). Entretanto, tal abordagem tem sido alvo de diversas críticas, que dizem respeito principalmente a uma suposta falta de caráter ou potencial político e/ou crítico. Tendo em vista tal contexto, o objetivo deste artigo é contrapor tais críticas às ideias forjadas nos trabalhos empíricos realizados por um dos autores que mais disseminaram e suscitaram discussões a respeito da TAR nos Estudos Organizacionais: John Law. Com isso, almeja-se, aqui, contribuir com subsídios para uma melhor compreensão da aplicabilidade da TAR nos estudos das organizações, destacando pontos que devem ser levados em consideração para que não sucumba às críticas a ela direcionadas; além disso, são discutidas algumas implicações dessa abordagem em trabalhos empíricos.
\end{abstract}

Palavras-chave: Teoria Ator-Rede. Epistemologia. Pós-estruturalismo.

\begin{abstract}
In recent years, much has been debated about alternatives to the so called "representational approaches" in studies of organizations. Such discussions usually highlight the procedural and fluid aspect of the organization,which cannot be taken as having an end or a static object and, thus, it requires other ways to exploit and understand its phenomenon. An approach emerging with considerable popularity is the Actor-Network Theory (ANT). However, this approach has been the target of much criticism, which is mainly related to an alleged lack of political and/or critical nature or potential. Given this context, this article aims to face such criticism to ideas forged in empirical works carried out by one of the authors who spread and triggered more discussions about ANT in Organizational Studies: John Law. By doing so, we intend, here, to contribute with means for a better understanding of the ANT applicability to studies of organizations, highlighting

Artigo submetido em 29 de abril de 2013 e aceito para publicação em 02 de setembro de 2013.

${ }^{1}$ Doutoranda e Mestre em Administração de Empresas pela Fundação Getulio Vargas/EAESP. Endereço: Rua General Osório, 1542, Cambuí, CEP 13010-111, Campinas-SP, Brasil. E-mail: mfcavalcanti@gmail.com

2 PhD em Business Administration pela Manchester Business School; Professor adjunto da Fundação Getulio Vargas/EAESP; Pesquisador visitante na University of Manchester; Professor Visitante no Gothemburg Research Institute. Endereço: Rua Itapeva, 474, $11^{\circ}$ andar, Departamento de Administração, Bela Vista, CEP 01332-000, São Paulo - SP, Brasil. E-mail: rafael.alcadipani@fgv.br
\end{abstract}


points that must be taken into account so that it does not collapse because of the criticism aimed at it; besides, we discuss some implications of this approach in empirical works.

Keywords: Actor-Network Theory. Epistemology. Post-structuralism.

\section{Introdução}

Desde meados do século passado, alternativas à ontologia representacional do mainstream nos estudos das organizações vêm sendo debatidas. Cooper (1976), com seu artigo "The Open Field", publicado no prestigioso Human Relations, foi um dos precursores neste sentido. Esse trabalho teve como objetivo definir uma epistemologia do processo que serviria como uma base necessária para o entendimento das ações humanas. Thanem (2001) afirma que, com esse trabalho, Cooper tornou-se um dos primeiros autores no campo dos estudos organizacionais a propor uma abordagem diferente para a compreensão do fenômeno organizacional, campo até então dominado pelas teorias sistêmicas, que percebem a organização como uma entidade com características bem definidas. A abordagem proposta por Cooper (1976) diferenciava-se das abordagens do mainstream teórico, uma vez que argumentava a favor da necessidade de se pensar a ação humana e o exercício do pensamento em termos difusos e processuais, em vez de tomá-los como fenômenos definidos por uma realidade previamente constituída, racional e objetiva. Para Cooper (1976), a abordagem tradicional mata, de antemão, a própria possibilidade de se pensar a respeito dos fenômenos que encontramos em nosso dia a dia, uma vez que são singulares e mutantes (e, portanto, processuais) em sua realização diária.

Dessa forma, o trabalho de Cooper (1976) abriu caminho para que categorias como "organização" e "estrutura" passassem a ser sistematicamente criticadas, uma vez que tais constructos são tomados como representações acuradas de objetos ou de uma realidade natural. A abordagem tradicional, dessa forma, é vista como uma abordagem que não subsidia a reflexão a respeito do processo por meio do qual as organizações e suas estruturas são construídas (COOPER e BURRELL, 1988). Sendo assim, aquela visão dominante das organizações presente no mainstream teórico era resultado de uma abordagem representacional que aos poucos passou a ser questionada neste campo com o surgimento de abordagens ontoepistemológicas distintas (ver ALCADIPANI e HASSARD, 2010; BEYES e STEYAERT, 2011; BURRELL e MORGAN, 1979; CUNLIFFE, 2010; LORINO, TRICARD e CLOT, 2011; MORGAN, 1990; MORGAN e SMIRCICH, 1980).

Uma abordagem com especial apelo empírico e que surge nesse contexto com considerável popularidade é a Teoria Ator-Rede (CALLON, 1986; CALLON e LATOUR, 1981; CZARNIAWSKA, 2006). Esta teoria (que aqui será chamada de TAR) baseia-se no mesmo pressuposto ontológico de Cooper (1976) e toma a organização não como um dado pronto ou uma instância absolutamente bem delimitada, estável e representável. Pelo contrário, foca-se no organizar ou na organização enquanto um processo instável, temporário, negociado, e nunca inteiramente manifestado (COOPER e LAW, 1995). Law (2007) pontua que a origem dessa visão de organização estaria vinculada ao pós-estruturalismo. Desse modo, a TAR tem sido utilizada como uma abordagem epistemológica para se compreender as organizações tanto no exterior quanto no Brasil. Porém, no campo dos Estudos Organizacionais em geral e no Brasil em particular, a TAR tem sido mais associada às ideias do sociólogo francês Bruno Latour do que às de John Law, que é um dos principais autores a aplicar a TAR nos estudos de organizações. Essa associação estrita das ideias da TAR aos escritos de Latour tem produzido uma repetição mecânica das análises feitas por este autor, contribuindo para que a 
TAR seja muitas vezes criticada por supostamente ser uma abordagem demasiado mecânica e apolítica (ver LEE e BROWN, 1994; WHITTLE e SPICER, 2008).

Frente a isso, o objetivo neste artigo é contrapor as críticas comumente direcionadas à TAR às ideias presentes nos trabalhos empíricos desenvolvidos por John Law. Defende-se, por meio do resgate das ideias presentes nos trabalhos de Law, que elas suscitam uma abordagem crítica aplicável aos estudos das organizações (por "crítica" entende-se uma abordagem desnaturalizada, reflexiva e não voltada à performance). Por meio dessa contraposição, busca-se, com este artigo, contribuir para uma melhor compreensão da aplicabilidade dessa perspectiva teórica em estudos empíricos no campo dos estudos organizacionais.

Para alcançar o objetivo proposto, primeiramente serão exploradas algumas definições da TAR e as principais críticas comumente direcionadas a esta abordagem. Depois, serão discutidos alguns trabalhos empíricos realizados por Law nos quais ficam evidentes tanto a existência de um olhar crítico e/ou político por parte do autor, quanto a vocação empírica da TAR. No último tópico, será analisado o potencial das ideias forjadas por Law para os estudos organizacionais, bem como serão abordados alguns princípios metodológicos básicos da TAR segundo a visão particular deste autor.

\section{Compreendendo a TAR e suas Críticas}

A Teoria Ator-Rede, também conhecida como "sociologia da translação" (LATOUR, 2005), surge originalmente no campo de estudos da ciência e tecnologia - Science and Technology Studies, ou STS (WOOLGAR, COOPMANS e NEYLAND, 2009). Nos estudos das organizações, a TAR surge após a abertura do campo a abordagens processuais, particularmente trazendo um apelo que the fornece um ponto de vista distinto das demais abordagens do tipo ao levar o pesquisador a focar não somente no elemento "humano" ou "social" das organizações, mas voltar-se também com igual atenção às materialidades que constituem sua realidade (ALCADIPANI e HASSARD, 2010; ALCADIPANI e TURETA, 2009; BLOOMFIELD e VURDUBAKIS, 1999; CZARNIAWSKA e HERNES, 2005; DUREPOS e MILLS, 2011; LAW, 1994).

Resumidamente, pode-se dizer que a TAR visa especialmente a "materialidades" (não simplesmente humanas) de redes heterogêneas que compõem o que ela chama de processo de translação. A translação é uma noção fundamental usada por estudiosos da TAR para examinar o processo de organização das redes heterogêneas. Essa noção busca dar conta do "[...] trabalho por meio do qual os atores modificam, deslocam, e transladam seus interesses diversos e contraditórios" (LATOUR, 1999, p. 20) na tentativa de se constituir como um todo coeso (CALLON, 1986; CALLON e LATOUR, 1981; LAW, 1999b). Callon (1986) explica que a translação é o mecanismo por meio do qual os atores de uma determinada rede constituem-se e tomam forma. Tais "translações" dão-se por meio de deslocamentos e transformações enquanto as identidades do ator, a sua possibilidade de interação e seus limites de manobra são negociados e delimitados (CALLON, 1986, p. 203). A noção de translação representa, assim, uma das principais ferramentas epistemológicas da TAR para analisar o estabelecimento de redes de atores heterogêneas (ver CALLON e LAW, 1982; LATOUR, 1988; 1992; LAW, 1994).

A noção de rede heterogênea está no coração da TAR (LAW, 1992; 1994). Frisa-se que, embora os atores possam ter um senso de estabilidade e singularidade, segundo a TAR este é um resultado alcançado quando diferentes materiais heterogêneos são agenciados em conjunto (CALLON, 1986; LAW 1992; 1999a). Em 
outras palavras, de acordo com esta abordagem, os atores tomam a sua forma e adquirem seus atributos como consequência de suas relações com os outros. Elas são realizadas em e por meio dessas relações (LAW, 1994; 1999a; 1999b).

Um exemplo empírico clássico do processo de translação analisado por adeptos da TAR é o laboratório (ver LATOUR e WOOLGAR, 1997; LAW, 1994; LYNCH, 1985). Segundo a TAR, o conhecimento científico, assim como qualquer outro objeto de estudo, é produto de um trabalho árduo por meio do qual pequenas partes e arranjos - tubos de ensaio, reagentes, organismos, animais, radiação, outros cientistas, outros laboratórios, computadores etc. - são submetidos a um processo de organização que os conjuga. A ciência e seu poder estariam, dessa forma, relacionados a um processo de "engenharia do heterogêneo", visto que partes do social, do técnico, do conceitual, do textual são conjugadas e, assim, convertidas ou "transladadas" em produtos científicos que, por sua vez, são também heterogêneos apesar de parecerem coesos e bem fechados em uma unidade.

No entanto, essa abordagem proposta pela TAR suscitou diversas críticas no decorrer dos anos. Walsham (1997) as resume em quatro críticas principais, que seriam: análise limitada das estruturas sociais; postura amoral ao negligenciar questões de cunho político e moral; falha ao considerar a distinção analítica entre humanos e não humanos; e possíveis problemas a respeito de como seguir as entidades numa análise das redes. Reed (1997) corrobora a visão de Walsham (1997) ao considerar que a TAR possuiria uma neutralidade crítica, e Whittle e Spicer (2008) apontam também uma suposta neutralidade política presente nessa abordagem (visão compartilhada por CASTREE, 2002). Além disso, estes últimos autores apontam que a visão de rede presente na TAR seria determinística, ou seja, uma visão que reificaria as relações sociais. Lee e Brown (1994) também afirmam que a TAR assumiu contornos determinísticos, uma vez que se tornou uma formulação metalinguística dentro da qual qualquer sequência de humanos e não humanos pode ser determinada sob os mesmos termos. Esclarece-se que a crítica à suposta neutralidade política da TAR está atrelada ao argumento de que, como um sistema totalizante e que busca perceber estabilizações numa rede por meio de sua noção de translação, não deixaria espaço para fazer aparecer diferenças ou produzir uma análise de como essas redes modificam-se e tornam-se outras (HINCHLIFFE, KEARNES, DEGEN et al., 2005).

Para que fosse possível desvencilhar-se dessas graves críticas, alguns autores realizaram certas torções analíticas na TAR atribuindo a alguns de seus conceitos sentidos que não necessariamente foram originalmente concebidos por Latour. Law e Singleton (2005), por exemplo, concentraram-se na ideia de objeto para argumentar contra a validade de tais críticas. Law (2002) explica que a TAR acarreta um olhar diferenciado sobre os objetos, e estes passam a ser considerados como contingentes de toda uma complexidade que necessita ser abarcada pela análise do pesquisador. $\mathrm{O}$ autor aponta que os objetos empíricos, vistos desta forma, não podem ser tomados como um fim em si mesmos (ou como "entidades"), mas como manifestações de arranjos mais ou menos estáveis de uma rede de relações que veio a possibilitar sua existência ou produzi-los (LAW, 1994). Segundo este olhar, o objeto adquire existência somente enquanto esta rede mais ou menos estável também existir (LAW, 1994; 1999b); visão que também vale para as organizações (COOPER e LAW, 1995). Ao assim fazê-lo, a TAR modifica a análise de objetos nas organizações.

Law e Singleton (2005) pontuam, todavia, que tal posicionamento exige certo cuidado. Isto se dá devido às críticas à TAR que dizem respeito ao fato de a abordagem supostamente enfatizar a compreensão de como as redes de relações e os objetos tornam-se "estáveis", sem levar em conta, consequentemente, uma série de outros arranjos (como elas se modificam, por exemplo). Para esses autores, no entanto, em termos 
conceituais essa não seria uma crítica válida, já que um objeto, segundo orientações gerais da TAR, seria da ordem de uma caixa-preta, que contém e/ou é contido por uma rede de infindáveis relações nunca inteiramente representáveis. Nem mesmo a distinção entre humano e não humano seria uma imposição de uma visão binária por parte da TAR, pois os objetos, segundo a teoria, seriam híbridos que não cessariam de misturar humanos e não-humanos (LAW, 1999a; LAW, 1994).

A respeito da visão de que o conceito de translação é uma reificação aplicável a qualquer situação, Law (1992) argumenta sobre a possibilidade de atribuir algumas estratégias gerais às translações, mas que, no entanto, estas são destinadas a "[...] se ramificarem por e reproduzem-se em uma série de situações ou localizações de redes" (LAW, 1992, p. 388). Descobrir como elas funcionam é, portanto, uma questão empírica e não uma pressuposição e/ou reificação teórica. No próximo tópico serão explorados alguns dos trabalhos empíricos de John Law com vistas a tornar mais clara essa visão particular da TAR levada a campo pelo pesquisador. A partir daí, finalmente, será avaliado se e/ou como essa visão se desvencilha das críticas sofridas pela TAR desde seu surgimento.

\section{A TAR vai a Campo: John Law e as Políticas do Organizar}

Law (1986b) produziu uma das análises documentais mais referenciadas da TAR nos estudos organizacionais. $\mathrm{O}$ objeto do pesquisador foi especificamente a expansão marítima portuguesa e como os portugueses foram capazes de estabelecer uma rota comercial estável para a Índia. O autor argumenta que esse processo só poderia ser entendido levando-se em conta como eles foram bem-sucedidos em criar um "envelope" capaz de viajar com segurança da Europa para o Oriente, e de volta.

Para Law (1986b), esse processo dependia do uso de um tipo específico de embarcação, muito versátil e difícil de ser atacada, com canhões poderosos, capaz de transportar uma quantidade considerável de carga e também de navegar rapidamente. Além disso, esse navio tinha equipes pequenas, o que exigia menos paradas durante as viagens. Mais importante, devido ao seu desempenho em durabilidade, mobilidade e disparo, era capaz de voltar a Portugal. A embarcação, no entanto, foi apenas um elemento da rede que constituía um "envelope". A conquista portuguesa também contou com a criação de um revolucionário sistema de navegação que possibilitou menor dependência em relação ao conhecimento geográfico europeu da época. A parte mais importante desse sistema foi o Regimento do Astrolábio e do Quadrante, que dava instruções para navegadores sobre como encontrar as coordenadas geográficas aproximadas usando alguns dispositivos (por exemplo, astrolábios, bússolas, mapas, etc.) e observações do céu.

Law (1986b) argumenta que a possibilidade de ação à distância depende do alinhamento de documentos, aparelhos, mapas, etc. Em outras palavras, depende do estabelecimento de uma rede de materiais heterogêneos, que permite, ao mesmo tempo, movimento e imutabilidade. A ação à distância é um elemento importante nas organizações, ela pressupõe basicamente a existência de um fenômeno que precisa ser controlado (como, por exemplo, a produção, absenteísmo de empregados, etc.) e o acúmulo de informações a respeito dele. Um ponto crucial para o estabelecimento e manutenção da ação à distância refere-se a como a informação é tratada. Torna-se difícil trabalhar uma informação que não segue qualquer modelo ou padrão (LATOUR, 1987), daí a importância da confecção de relatórios gerenciais, por exemplo.

Outro importante estudo feito por Law iniciou-se em 1988, quando o autor deu início a uma pesquisa buscando compreender a organização, gestão e o sucesso de mercado da ciência. Definido o tema de pesquisa, Law saiu em busca de acesso a um grande laboratório para conduzi-la. Valendo-se do conceito de 
"pequenas narrativas", na primeira história o autor narra como o acesso foi obtido. Por meio dessa história, o pesquisador destacou não só o papel importante de seu contato na universidade, que lhe apresentou os membros do conselho de gestão do laboratório, mas também a importância de seu projeto de pesquisa e de como ele foi apresentado apropriadamente nas reuniões de negociação para o acesso com diversos gerentes do laboratório. Law (1994) conclui que o que culminou com a aprovação de seu acesso foi sua habilidade em conjugar uma série de "bits and pieces" em favor de seu projeto.

O autor permaneceu no campo por um ano e relatou seu crescente envolvimento com o laboratório, com as pessoas que ali trabalhavam. Destacou também alguns pontos que identificou como prejudiciais à sua pesquisa, como o acordo, durante a negociação de acesso, de que qualquer publicação resultante da pesquisa seria antes apresentada à direção do laboratório, bem como seu próprio sentimento de pertença e apego às pessoas que ali trabalhavam. $\mathrm{O}$ autor percebeu que tais fatores passaram a afetar diretamente sua capacidade de escrever pontos de vista que poderiam vir a prejudicar a instituição. Para lidar com essa ambivalência, o autor relata ter procedido de forma a focar em "eventos" no laboratório relacionados à teoria social. Isso tirou, portanto, o foco do laboratório em si, como entidade, e direcionou seu olhar a eventos específicos (LAW, 1994, p. 39).

Mais especificamente, o motor de sua análise veio das práticas de organizar do laboratório, dos "sonhos" de ordem dos gerentes e de como estes o organizavam. Para tanto, Law (1994) conduziu uma etnografia. Os primeiros relatos da pesquisa passam, nesse sentido, às dificuldades trazidas por esta abordagem, às ansiedades causadas e à forma como o pesquisador lidou com ela. $\mathrm{O}$ autor relata que a maior parte dos acontecimentos ocorridos no laboratório durante o tempo de campo não foi contabilizada como dado para sua pesquisa. Isso ocorreu pelos seguintes motivos: eles não foram presenciados pelo pesquisador; não pareceram importantes; houve falha em anotar/gravar os acontecimentos e o pesquisador esqueceu-se deles; o pesquisador não compreendeu seu sentido; etc. Outra questão envolvida no problema de transformar acontecimentos em dados diz respeito ao próprio sistema de translação envolvido nesse processo, que não oferece garantias de fidedignidade ao acontecimento.

Ao relatar sua experiência em campo, Law (1994) afirma que realizar uma etnografia foi uma experiência que consistia em ver, ouvir, notar, sentir, cheirar e, então, tomar tudo e tentar dar sentido às coisas (o que, muitas vezes, significou reconhecer que muitas coisas não faziam sentido). E tais "coisas" percebidas em campo, na visão do autor, não passariam de efeitos relacionais mutantes, produtos de redes dinâmicas e, não, de estruturas sincrônicas. Se algo, então, se estabiliza por um momento, a ponto de ser visto ou notado (ou cheirado, sentido, etc.), deve-se a uma estabilidade pragmática temporária.

Além disso, o autor relata a importância das histórias do laboratório para sua pesquisa, já que, segundo sua visão, falam muito mais a respeito dos modos de organizar do presente do que do passado. Elas justificam e explicam o presente, consubstanciando as redes de atores que compõem a organização do laboratório (LAW, 1994). Com isso em mente, o pesquisador destrinchou os modos de organizar da então liderança do laboratório e como as decisões eram tomadas. $\mathrm{O}$ autor concluiu que este processo era regido, principalmente, pela realização de simplificações necessárias que tornavam possível a tomada de decisão.

Mol e Law (1994), em outro estudo empírico, analisaram a anemia na Holanda e na África concomitantemente. Os pesquisadores retrataram a dificuldade, na África, em constituir a rede necessária para testar cientificamente os níveis de hemoglobina no sangue dos pacientes. A alternativa dos médicos era diagnosticar a anemia clinicamente de maneira simples (olhando as pálpebras e verificando se elas apresentavam cor amarela, por exemplo). Já a Holanda tinha tais redes disponíveis e facilmente utilizáveis. 
Além disso, quando médicos holandeses iam para a África e se deparavam com a realidade ali presente, concluíam que os próprios sintomas que clinicamente possibilitariam a realização do diagnóstico mudavam, já que na África um paciente com sintomas de cansaço, abatimento, dificuldade em respirar poderia estar sendo acometido de males diversos e diferentes dos encontrados em pacientes na Holanda. Este é um exemplo de como um mesmo objeto é mutável em contingências locais específicas, justamente devido às redes heterogêneas que o constituem.

Outro exemplo de objeto mutável foi abordado em um artigo escrito em parceria com Singleton (LAW e SINGLETON, 2005). Os autores analisaram o caso de uma bomba de água instalada em uma vila no Zimbabwe. Law e Singleton (2005) pontuam que a bomba modificava-se (em termos de aparência e funcionamento) segundo as circunstâncias do local onde era instalada. Tal característica adaptativa era a razão de sua ampla utilização em muitas vilas do Zimbabwe (LAW, 2004; LAW e SINGLETON, 2005).

Observa-se que considerar objetos como uma organização mutável ou fluida implica dizer que sobre eles não existe um ponto de vista privilegiado, já que nunca se mostram bem definidos ou com contornos nítidos. Apesar disso, em outro trabalho que buscou investigar empiricamente a organização da "doença do fígado causada por alcoolismo", Law e Singleton (2005) afirmam que há a necessidade de conservar uma continuidade que vai além da fluidez, e esta (conforme visto no exemplo da bomba no Zimbabwe) tende justamente a fortalecer os objetos (LAW e SINGLETON, 2005).

Dessa forma, no que diz respeito aos estudos das organizações, olhar a organização como processo não pressupõe um possível "enfraquecimento" desse conceito, mas, ao contrário, tal abordagem ressalta que é por meio de sua fluidez e plasticidade que a organização melhor exerce poder e adquire robustez. Law e Singleton (2005) afirmam que pesquisar esse tipo de objeto (sejam organizações ou a doença do fígado causada por alcoolismo) é algo factível, mas que, no entanto, tal empreitada exigiria um tipo de radicalismo ontológico e metodológico.

Tal radicalismo requerido por objetos fluidos como os aqui citados reforçam a necessidade, já colocada por Law, segundo a sua visão da TAR, de tratar a complexidade na prática, ou empiricamente. Ao abordar tal necessidade, Mol e Law (1994) retornam, então, à ideia de modos de organizar presente em Law (1994) e afirmam que tais modos de organizar trazem consigo toda uma multiplicidade de relações complexas existentes em uma determinada rede, daí a necessidade de serem compreendidos na prática. Law (1999a; 2002; 2004) tentou dar conta dessa noção de multiplicidade por meio da noção de fractal. Segundo o autor, um fractal é um objeto que ocupa mais de uma e menos do que muitas dimensões. Essa ideia foi utilizada pelo pesquisador para tentar dar conta de um projeto aeronáutico que falhou na Grã-Bretanha. (LAW e CALLON, 1988). A necessidade de compreender os modos de organizar empiricamente foi novamente pontuada por Law e Urry (2004). Os autores afirmam que, mesmo se estamos tratando de uma postura empiricista de produzir conhecimento a respeito da complexidade, uma abordagem metodológica não representa ou acessa uma realidade previamente constituída, mas uma metodologia participa e é expressão de uma realidade própria à postura metodológica adotada.

Este ponto é muito importante, pois diz respeito à crítica feita por Whittle e Spicer (2008) e outros autores a uma suposta neutralidade política da TAR. Uma vez que abordagens metodológicas "criam" realidades e, assim, estão diretamente envolvidas no processo de criação do real, pressupõe-se que métodos são imediatamente políticos. A respeito dessa preocupação com o que chamaram de uma "política ontológica", os autores afirmam que a ciência social (como pode ser entendido esse tipo de análise organizacional) é capaz de realizá-la. Mas, para isso, necessita de ferramentas para compreender o complexo e o elusivo. A TAR é, portanto, um esforço nesse sentido, na medida em que vai além de velhas categorias como a estrutura 
e fornece ferramentas analíticas para a compreensão de objetos fluidos e mutantes, segundo a visão particular de Law. A necessidade de tal política ontológica ficou especialmente clara no estudo empírico de Law e Singleton (2005) a respeito da doença do fígado causada pelo alcoolismo, uma vez que este objeto apresentava uma ontologia mutante (sobre a questão ontológica de objetos mutantes, ver também Mol, 2002).

Em outro trabalho que destaca claramente esse ponto, Law e Mol (2008) investigaram a política presente no processo de fervura de lavagem para porcos. Utilizando subsídios teóricos da TAR e do pós-colonialismo, os autores argumentam que tal fervura era uma técnica política em, pelo menos, três aspectos: dividia pobres e ricos (classificando países onde há doenças endêmicas e onde não há); unia diferentes temporalidades (técnicas antigas de agricultura e técnicas contemporâneas) e lugares (a Inglaterra com o restante do mundo); era uma maneira de limitar a escassez de comida em escala mundial, uma vez que possibilitava a reciclagem de comida.

Em resumo, e conforme pontuado por Alcadipani e Hassard (2010), a TAR vista de tal perspectiva oferece uma base analítica para as "políticas do organizar". Todavia, ao propor que tal base deve ser utilizada "na prática", não impõe uma solução geral a todas as questões conforme argumento de alguns críticos (HINCHLIFFE, KEARNES, DEGEN et al., 2005; LEE e BROW, 1994; WALSHAM, 1997; WHITTLE e SPICER, 2008), mas frisa que intervenções políticas podem apenas ser feitas localmente e empiricamente, jamais podendo servir como base para uma teoria que visa ser universal. Isso possibilita refletir que práticas nefastas como opressão do trabalhador, assédio moral, trabalho em condições análogas a escravidão e tantas outras não são naturais, mas produzidas em contextos e situações específicas e, por isso, poderiam ser diferentes.

Contra as críticas voltadas especificamente a um suposto caráter neutro apolítico da TAR, Law (1991) argumenta que aceitar o relativismo epistemológico não implica o relativismo político em si. Dessa forma, ele argumenta que as consequências do organizar devem ser entendidas em termos das inclusões e exclusões que são criadas, bem como dos seus efeitos. Para ele, a política da TAR trata das distribuições hierárquicas, ou seja, de como ordens específicas criam inclusões e exclusões específicas que são realizadas de forma heterogênea (ver LAW, 1997). Usando o colonialismo como exemplo, Law (1997) afirma que o fato de o colonialismo não ser um sistema único tende a torná-lo uma distribuição muito mais forte, o que implica que dominações são sempre multiplamente realizadas pelo conjunto de diferentes tipos de relações. Sendo assim, falar sobre heterogeneidades é um esforço político (LAW, 1997). No próximo tópico serão pontuadas, de forma mais específica, as implicações desse olhar nos estudos de organizações.

\section{A TAR nos Estudos das Organizações segundo John Law: um Olhar Voltado às Mecânicas do Poder e aos Modos de Organizar}

Contrariamente às críticas de que a TAR seria uma abordagem acrítica, Law (1992) buscou demonstrar por meio de sua noção de modos de organizar que essa abordagem estaria voltada a compreender as "mecânicas do poder". No caso específico do estudo das organizações, pode-se dizer que quaisquer que sejam as organizações a serem estudadas (da IBM a um pequeno negócio de bairro, por exemplo), isso deve ser feito da mesma forma ou pelo mesmo viés. Sendo assim, se a IBM é maior e mais poderosa do que a padaria do bairro, deve-se estudar como isso se deu, a mecânica do poder que sustentou e/ou sustenta esta diferença. O autor não afirma, todavia, que não existam diferenças entre as duas organizações hipoteticamente colocadas aqui. Ao contrário, ele observa que justamente essa diferença deve ser questionada, ou seja, são as especificidades de cada uma dessas organizações que precisam ser consideradas. No caso aqui colocado, a diferença entre a IBM e a padaria do bairro está no fato de que a primeira parece ter adquirido uma existência "macrossocial", que acaba por tornar nebulosa a mecânica do poder que culminou no surgimento da IBM como entidade. Law (1992) argumenta que o ponto central da TAR seria sua preocupação relativa a "como" atores e organizações mobilizam, sobrepõem e dão coesão à infinidade de pequenas peças que os compõem. 
Isto é, ao analisar redes heterogêneas por meio da TAR, a preocupação central reside em como estes arranjos formados por pequenas partes conseguem mantê-las unidas e coesas de tal forma que conseguem fazer as vezes de "um" ator pontual (e não meramente um conjunto de peças).

Além disso, Law (1986b) definiu a questão da mecânica do poder aqui colocado como sendo uma análise sobre como atores e coletividades tentam constantemente dominar agentes e objetos naturais que podem resistir a tal investida. Essa visão seria convergente à noção de poder de Foucault, por exemplo, que pressupõe que toda relação de poder implica resistências primordiais e um jogo de enfrentamentos que corroboram uma visão relacional imediatamente política (BRANCO, 2011; FOUCAULT, 1988; 1999). Nesse sentido, Law (1994) explica que, na TAR, o interesse estaria em uma análise simétrica da "organização" cujo foco de análise é colocado nas artimanhas e estratégias que levaram os grandes e poderosos a se tornarem grandes e poderosos. Há, portanto, um rechaçamento por parte do autor à crítica de que a TAR seria politicamente neutra, uma vez que, em tal abordagem, a análise se centraria nas artimanhas dos poderosos.

Todavia, segundo Alcadipani e Hassard (2010), o poder seria para essa abordagem apenas uma de suas lentes analíticas, não uma analítica que privilegie esse conceito ou a noção de relações de poder como "o" elemento capaz de explicar uma organização ou quaisquer objetos. Segundo Alcadipani e Hassard (2010), a questão política na TAR foi tratada no notório debate "TAR e Depois" (Actor-Nectwork Theory and After), realizado em destaque na publicação de Law e Hassard (1999). Neste livro, Law (1999b) argumenta que determinadas críticas apenas fazem sentido se a TAR é tomada como uma teoria "morta", ou quase como uma "religião", com um território delimitado que precisa ser defendido (não se descarta, todavia, que isso tenha ocorrido em alguns casos, como nos casos em que a TAR foi aplicada de forma a se assemelhar mais com teoria institucional do que com uma teoria crítica). Pontua-se, todavia, que tal condição seria contraditória ao próprio motor da TAR, que é sua capacidade de dar conta de complexidades relegadas quando há instâncias privilegiadas de análise.

Além disso, vale pontuar que a noção de modos de organizar aproxima-se em parte da noção de "pequenas narrativas" de Lyotard (1986), um dos mais proeminentes autores a pensar o pós-modernismo. A utilização dessa noção ficou bastante clara no trabalho empírico conduzido por Law (1994) no laboratório, conforme visto no tópico anterior. Todavia, Law opta por não utilizar tal conceito de forma estrita para, segundo ele, não passar a impressão de que as narrativas por ele tratadas seriam apenas uma maneira de falar sobre o mundo (LAW, 1994). Em vez disso, ele frisa o caráter material da noção de modo de organizar, que se refere a padrões recursivos encarnados, testemunhados, gerados e reproduzidos como manifestações da rede heterogênea de relações humanas e não humanas que constituem uma organização. Assim, um modo de organizar vai além de uma mera narrativa, é necessário levar em conta toda a complexidade das relações existentes entre humanos e não humanos em uma rede de atores.

É nesse sentido, também, que Law (1999b) argumenta que a TAR é uma "semiótica da materialidade". Para Law (2002), o aspecto relacional que caracteriza a existência dos objetos aproxima-se da abordagem semiótica pós-estruturalista, uma vez que, segundo esta, um termo adquire sentido somente por meio das relações que ele estabelece em uma rede de significantes. Outro aspecto que aproxima a TAR de uma abordagem pós-estruturalista diz respeito ao ponto em que a primeira distancia-se do estruturalismo, ou seja, ao apelo pós-estruturalista de considerar o contexto material mais amplo nessa rede de relações (isto é, ao considerar redes heterogêneas de relações). Percebe-se que, no entanto, a TAR se afasta de uma abordagem pós-estruturalista no sentido estrito comumente encontrado nos estudos organizacionais - estudos que privilegiam a instância linguística sobre as demais para compreender as organizações - (ver JONES, 2009). Conclui-se, até mesmo, que a utilização da TAR nos estudos das organizações pode ser considerada uma resposta à crítica de que abordagens pós-estruturalistas possuem um foco excessivo em elementos linguísticos (ver REED, 2000).

Argumenta-se que a TAR fornece meios analíticos para identificar os modos de organizar de redes de atores, isto é, padrões recursivos encarnados, testemunhados, gerados e reproduzidos por uma rede de atores. 
Conforme afirmam Alcadipani e Hassard (2010), a TAR pode ser vista como uma abordagem metodológica, já que ela oferece um ponto de vista singular que tanto diz respeito a uma postura do pesquisador ao ir a campo, quanto lhe oferece uma série de ferramentas analíticas para a produção de conhecimento narrativo a respeito de organizações ou outros fenômenos.

Law contribui enormemente para a aplicabilidade da TAR como abordagem metodológica ao apresentar alguns princípios metodológicos que a conduzem (LAW, 1986b; 1994) e que podem ser identificados em seus trabalhos empíricos. O primeiro deles seria o princípio de simetria, cuja base está na afirmação de que "tudo" merece uma explicação (nos estudos sobre a prática científica, por exemplo, tanto as origens do conhecimento verdadeiro quanto as do falso merecem ser explicadas). Segundo essa lógica, deve-se questionar, ainda, por que há uma distinção entre atores humanos e não humanos (já que não se pode assumir nenhuma diferença essencial contida na natureza das coisas).

O segundo princípio metodológico seria o não reducionismo, que imprime uma crítica à prática padrão da sociologia moderna de explicar uma grande diversidade de fenômenos - como, por exemplo, o "social" em Latour (2005), ou a "classe operária", etc.. Adotar tal princípio acarreta um compromisso de partir para o campo sem conceitos prontos ou reduções a priori. Outro princípio destacado por Law (1994) diz respeito à visão processual, contingente e precária do objeto analisado. Ou seja, nada pode ser encarado como necessariamente estável, e sua própria consistência é um produto da rede de relações que o formam.

O autor sugere, ainda, a reflexividade como outro princípio metodológico. Law (1994) afirma que a reflexividade pode ser vista como uma extensão do princípio de simetria, e diz respeito ao fato de que o pesquisador não pode considerar-se diferente daquilo que está sendo estudado, ou seja, ele não ocupa um lugar privilegiado na análise e também é considerado parte da rede de atores.

Conclui-se que, embora seja difícil definir a TAR (LEE e HASSARD, 1999) e que, enquanto adotada, tal perspectiva possui uma característica mutante (LAW, 1994), os diferentes trabalhos que a adotam no campo empírico possuem alguns aspectos compartilhados (LATOUR, 1987; 1999; 2005; LAW, 1992; 1999a; 2007). Tais aspectos tendem a estar parcialmente presentes nas análises acadêmicas influenciadas por essa perspectiva e, de acordo com a posição aqui adotada, eles podem servir como guia para aqueles que queiram aplicar esse olhar nos estudos organizacionais.

\section{Considerações Finais}

Neste trabalho, vimos que John Law foi um autor que muito contribuiu para o desdobramento da TAR nos estudos organizacionais, não somente por apresentar argumentos que rebatem críticas comumente feitas a tal abordagem nesse campo do conhecimento, mas também por nunca ter deixado de pensar criticamente a respeito dessa abordagem, realizando ressalvas e pequenas torções analíticas que possivelmente deram novos sentidos a importantes conceitos da TAR, como foi o caso do conceito de translação. $\mathrm{O}$ autor também contribuiu para que a TAR se tornasse mais compreensível como abordagem metodológica, possibilitando que outros trabalhos empíricos como os desenvolvidos por ele sejam multiplicados nos estudos organizacionais.

A preocupação e o zelo ao levar seu pensamento para campo ressaltaram importantes características da TAR quando esta realiza seu potencial empírico. Observou-se, com isso, como o processo de pesquisa acaba por se desdobrar em um processo de intervenção política (que deve ser pensado cuidadosamente tanto em seu nível ontológico quanto metodológico). A necessidade de se pensar a respeito das nuances da "política do organizar" e de sua exploração empírica foi, portanto, um dos pontos cruciais trazidos pelos trabalhos de Law aqui tratados. Tal necessidade está em consonância com a potencial contribuição da TAR aos estudos organizacionais críticos, uma vez que, segundo a visão do principal autor aqui tratado, ela fornece uma base 
ontológica e/ou metodológica que busca acolher a complexidade e permite tratar de uma gama extremamente variada de temas na análise processual das organizações.

\section{Referências}

ALCADIPANI, R.; HASSARD, J. Actor-Network Theory, organizations and critique: towards a critique of organizing. Organization, v. 17, n. 2, p. 419-435, 2010.

; TURETA, C. Teoria ator-rede e estudos críticos em administração: possibilidades de um diálogo. Cadernos EBAPE.BR, v. 7, n. 3, p. 406-418, 2009.

BEYES, T.; STEYAERT, C. The ontological politics of artistic interventions: implications for performing action research. Action Research Journal, v. 42, n. 5, p. 521-536, 2011.

BLOOMFIELD, B. P.; VURDUBAKIS, T. The outer limits: monsters, actor networks and the writing of displacement. Organization, v. 6, n. 4, p. 265-649, 1999.

BRANCO, G. C. Os nexos entre subjetividade e política. In: BRANCO, G. C.; VEIGA-NETO, A. (Orgs.). Foucault Filosofia \& Política. São Paulo: Autêntica Editora, 2011. 13-17 p.

BURRELL, G.; MORGAN, G. Sociological paradigms and organizational analysis. Hants: Ashgate Publishing Limited, 1979.

CALLON, M. Some elements of a sociology of translation - domestication of the scallops and the fishermen of StBrieuc Bay. Sociological Review Monograph, p. 196-233, 1986.

; LATOUR, B. Unscrewing the big leviathan: how actors macro-structure reality and how sociologists help them do so. In: KNORR-CETINA, K.; CICOUREL, A. (Eds.). Advances in social theory and methodology: toward an integration of micro and macro sociologies. Londres: Routledge, 1981. p. 277-303.

; LAW, J. On interests and their transformation - enrollment and counter-enrollment. Social Studies of Science, v. 12, n. 4, p. 615-625, 1982.

CASTREE, N. 'False Antitheses? Marxism, Nature and Actor-Networks'. Antipode, v. 34, n. 1, p. 111-135, 2002.

COOPER, R. The open field. Human Relations, v. 29, n. 11, p. 999-1017, 1976.

; BURRELL, G. Modernism, postmodernism and organizational analysis: an introduction. Organization Studies, v. 9, n. 1, p. 91-112, 1988.

; LAW, J. 'Organization: distal and proximal views'. Research in the Sociology of Organizations, v. 13, p. 237-74. Greenwich, CT: JAI Press, 1995.

CUNLIFFE, A. Crafting Qualitative research: Morgan and Smircich 30 years on. Organizational Research Methods, Online First, p. 1-27, 2010.

CZARNIAWSKA, B. Reassembling the social: an introduction to actor-network theory. Organization Studies, v. 27, n. 10 , p. $1553-1557,2006$.

; HERNES, T. Constructing macro actors according to ANT. In: CZARNIAWSKA, B.; HERNES, T. (Eds). Actor-Network Theory and Organizing. Malmo: Elanders Berlings, 2005. p. 7-13.

DUREPOS, G.; MILLS, A. J. Actor-Network Theory, ANTi-History and critical organizational historiography. Organization, online first, p. 1-19, 2011.

FOUCAULT, M. História da sexualidade: a vontade de saber. Rio de Janeiro: Editora Graal, 1988.

A verdade e as formas jurídicas. Rio de Janeiro: Editora Nau, 1999. 
HINCHLIFFE, S. et al. Urban wild things: a cosmopolitical experiment. Environment and planning: society and space, v. 23, n. 3, p. 643-658, 2005.

JONES, C. Poststructuralism in critical management studies. In: ALVESSON, M; BRIDGMAN, T.; WILLMOTT, H. (Eds.). The Oxford Handbook of Critical Management Studies. Oxford: Oxford University Press, 2009. 76-98 p.

LATOUR, B. Science in action: how to follow scientists and engineers through society. Milton Keynes: Open University Press, 1987.

The pasteurization of France. Cambridge: Harvard University Press, 1988.

Power, discretion and strategy. In: LAW, J. (Ed.). A Sociology of monsters? Essays on power, technology and domination. Londres: Routledge, 1991. 165-191 p.

Where are the missing masses? Sociology of a few mundane artefacts. In: BIJKER, W.; LAW, J. (Eds). Shaping technology, building society: studies in sociotechnical change. Cambridge: MIT Press, p. 225-258, 1992.

On recalling ANT. In: LAW, J.; HASSARD, J. (Eds.). Actor Network Theory and After. Oxford: Blackwell/The Sociological Review, p. 15-26, 1999.

Reassebling the Social: an introduction to Actor Network Theory. Oxford: Oxford University PRESS, 2005.

.; WOOLGAR, S. Vida de Laboratório. Rio de Janeiro: Relume Dumara, 1997.

LAW, J. On power and its tactics - a view from the sociology of science. Sociological Review, v. 34, n. 1, p. 1-38, 1986a.

. On the methods of long-distance control - vessels, navigation and the portuguese route to India. Sociological Review Monograph, p. 234-263, 1986b.

. Notes on the theory of the Actor-Networking: ordering, strategy and heterogeneity. Systems Practice, v. 5, n. 3, p. 379-373, 1992.

Organizing Modernity. Oxford: Blackwell Publishers, 1994.

. After ANT: complexity, naming and topology. In: LAW, J.; HASSARD, J. (Eds.). ANT and After. Oxford, Blackwell/Sociological Review. p.1-14, 1999b.

Situating technoscience: an inquiry into spatialities. Environment and Planning D-Society \& Space, v. 19, n. 5, p. 609-621, 2001.

Objects and spaces. Theory, Culture, Society, v. 19, n. 5/6, p. 91-105, 2002.

Heterogeneities. 1997. Disponível em: <http://www.comp.lancs.ac.uk/sociology/papers/LawHeterogeneities.pdf>. Acesso em: 11 dez. 2004.

Objects, spaces and others. 1999a. Disponível em: <http://www.comp.lancs.ac.uk/sociology/papers/LawObjects-Spaces-Others.pdf>. Acesso em: 10 maio 2004.

After method: mess in social science research. Londres: Routledge, 2004.

Actor Network Theory and Material Semiotics. 2007. Disponível em: <http://www.heterogeneities.net/publications/Law-ANTandMaterialSemiotics.pdf>. Acesso em: 05 set. 2007.

; CALLON M. Engineering and sociology in a military aircraft project: a network analysis of technical change. Social Problems, v. 35, n. 2, p. 284-297, 1988. 
; MOL, A. Globalisation in practice: on the politics of boiling pigswill. Geoforum, v. 39, n. 1, p. 133-143, 2008.

; SINGLETON, V. Object lessons. Organization, v. 12, n. 3, p. 331-355, 2005.

; URRY, J. Enacting the Social. Economy and Society, v. 33, n. 3, p. 390-410, 2004.

LEE, N.; BROWN, S. Otherness and the Actor Network - the undiscovered Continent. American Behavioral Scientist, v. 37, n. 6, p. 772-790, 1994.

; HASSARD, J. Organization unbound: Actor-network theory, research strategy and institutional flexibility. Organization, v. 6, n. 3, p. 391-404, 1999.

LORINO, P.; TRICARD B.; CLOT, Y. 'Research methods for non-representational approaches of organizational complexity: the dialogical and mediated inquiry'. Organization Studies, v. 32, n. 6, p. 769-801, 2011.

LYNCH, M. Act and artifact in laboratory of science. Londres: Routledge, 1985.

LYOTARD, J. O pós-moderno. Rio de Janeiro: José Olympio, 1986.

MOL, A. The body multiple: ontology in medical practice. Durham: Duke University Press, 2002.

; LAW, J. Regions, networks and fluids - anemia and social topology. Social Studies of Science, v. 24, n. 4, p. 641-671, 1994.

MORGAN, G. Paradigm diversity in organizational research. In: HASSARD, J.; PYM, D. (Eds.). The theory and philosophy of organizations. Londres: Routledge, 1990. 13-29 p.

In praise of duality and dualism: rethinking agency and structure in organizational analysis. Organization Studies, v. 18, n. 1, p. 21-42, 1997. 1980.

; SMIRCICH, L. The case for qualitative research. Academy of Management Review, v. 5, n. 4, p. 491-500,

REED, M. The limits of discourse analysis in organizational analysis. Organization, v. 7, n. 3, p. 524-530, 2000.

THANEM, T. Processing the body: a comment on Cooper. Ephemera, v. 1, n. 4, p. 348-66, 2001.

WALSHAM, G. Actor-network theory and IS research: current status and future prospects. In: LEE, A.; LIEBENAU, J.; DEGROSS, J. (Orgs.). Information systems and qualitative research. London: Chapman and Hall, 1997, p. 467480 .

WEICK, K. The social psychology of organizing. New York: McGraw-Hill, 1967.

WHITTLE, A.; SPICER, A. Is Actor Network Theory Critique? Organization Studies, v. 29, n. 4, p. 611-629, 2008.

WOOlGAR, S.; COOPMANS, C.; NEYLAND, D. Does STS Mean Business? Organization, v. 16, n. 1, p. 5-30, 2009. 